East Tennessee State University

Digital Commons@ East Tennessee State University

ETSU Faculty Works

Faculty Works

6-30-2018

\title{
Analysis of Tweets Mentioning Scholarly Works from an Institutional Repository
}

Ashley D.R. Sergiadis

East Tennessee State University, sergiadis@etsu.edu

Follow this and additional works at: https://dc.etsu.edu/etsu-works

Part of the Scholarly Communication Commons

\section{Citation Information}

Sergiadis, Ashley D.R.. 2018. Analysis of Tweets Mentioning Scholarly Works from an Institutional Repository. Journal of New Librarianship. Vol.3(1). 130-150. https://doi.org/10.21173/newlibs/4/27 ISSN: 2471-3880

This Article is brought to you for free and open access by the Faculty Works at Digital Commons @ East Tennessee State University. It has been accepted for inclusion in ETSU Faculty Works by an authorized administrator of Digital Commons @ East Tennessee State University. For more

information, please contact digilib@etsu.edu. 


\section{Analysis of Tweets Mentioning Scholarly Works from an Institutional Repository}

\section{Creative Commons License}

Creative

This works is licensed under a Creative Commons Attribution 4.0 License.

Attribution

4.0

License 


\title{
Analysis of Tweets Mentioning Works from an Institutional Repository
}

\section{Ashley Sergiadis}

East Tennessee State University

\begin{abstract}
Altmetrics derived from Twitter have potential benefits for institutional repository (IR) stakeholders (faculty, students, administrators, and academic libraries) when metrics aggregators (Altmetric, Plum Analytics) are integrated with IRs. There is limited research on tweets mentioning works in IRs and how the results impact IR stakeholders, specifically libraries. In order to address this gap in the literature, the author conducted a content analysis of tweets tracked by a metrics aggregator (Plum X Metrics) in a Digital Commons IR. The study found that the majority of tweets were neutral in attitude, intended for a general audience, included no hashtags, and were written by users unaffiliated with the works. The results are similar to findings from other studies, including low numbers of tweeted works, high numbers of tweets neutral in attitude, and evidence of self-tweets. The discussion addresses these results in relation to the value of tweets and suggested improvements to Twitter metrics based on IR stakeholders' needs.
\end{abstract}

Keywords: altmetrics, institutional repositories, academic libraries, Twitter, PlumX Metrics, Digital commons

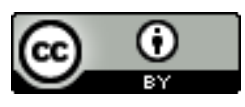

This is an Open Access article distributed under the terms of the Creative Commons Attribution 4.0 International License (http://creativecommons.org/licenses/by/4.0), which permits unrestricted use, distribution, and reproduction in any medium, provided the original work is properly cited. 


\section{Introduction}

Academic libraries have the capability to produce complex representations of higher education institutions' research impact by integrating institutional repositories (IRs) with metrics aggregators (e.g. Altmetric and Plum Analytics). Since the purpose of IRs is to collect the institutions' scholarly output, stakeholders across campus can benefit from these metrics including: faculty and students authoring content, administrators monitoring the institutions' research impact, and academic libraries managing IRs. Altmetrics (non-traditional metrics from the social web) particularly align well with the goals of IRs due to their immediate accumulation after online publication and representation of a broad audience (Holmberg, Haustein, \& Beucke, 2015). These characteristics match IRs' promotion of open access publishing, specifically in terms of grey literature (e.g. presentation slides, postprints, student research) that may not receive traditional metrics (e.g. citations) (Bernal, 2013; Holmberg et al., 2015; Konkiel \& Scherer, 2013). Altmetrics have been noted to indicate many attributes, including online impact, reach, visibility, attention, interest, distribution, promotion, and/or consumption of institutions' scholarly outputs (Barnes, 2015; Eysenbach, 2011; Holmberg et al., 2015; Ortega, 2016). IR stakeholders potentially can use altmetrics to showcase achievements, evaluate research, and discover scholarly outputs and/or other researchers (National Information Standards Organizations [NISO], 2016).

Literature on altmetrics has steadily been on the rise since the term was coined in 2010 (Erdt, Nagarajan, Sin, \& Theng, 2016). In comparison to bibliometrics, research is in its early stages and many topics have not been explored in-depth. Specifically, research has not focused on altmetrics provided by metrics aggregators integrated with IRs. Research examining altmetrics within IRs should be targeted since it can help stakeholders understand the meaning of altmetrics available through their IRs. To address these gaps in the literature, the author examined altmetrics from Twitter, a free networking microblogging service, where users tweet information in short bursts of 140 characters (recently expanded to 280 characters) to their followers. The primary metrics aggregators, Altmetrics and Plum Analytics, offer quantitative and qualitative data from Twitter. Plum Analytics (2018) provides the number of tweets and retweets (i.e. reposted tweet). Altmetric (2017b) provides the number of tweets, retweets, and quoted tweets. Altmetric (2017a) also details the number of Twitter users who tweeted about the work, including their demographic information (geographical location and user category) and number of followers. Both provide the content of the tweets. The author evaluated 
tweets collected from PlumX Metrics (a product of Plum Analytics) that mention works from a Digital Commons IR. The small scale research study was based on the following questions:

1. What are the attitudes (neutral, positive, negative) of the tweets?

2. Are the tweets' authors affiliated with the works?

3. Are the tweets intended for a general or specific audience?

4. What hashtags are in the tweets?

The author used content analysis to address the questions. The results produced a comprehensive overview of the tweets. While these results cannot be considered universal, they spark a discussion on the value of tweets and suggested improvements to Twitter metrics based on stakeholders' needs.

\section{Literature Review}

Relevant literature to the current study has either focused on sentiment and/or content analyses of tweets mentioning scholarly works or the relationship between altmetrics and institutional repositories (IRs). Due to the topics rarely overlapping, gaps in the literature exist related to altmetrics and IRs, specifically tweets that mention scholarship available in IRs.

\section{Sentiment and Content Analyses of Tweets}

In an analysis on the correlation between tweets and citations, Eysenbach (2011) remarked on the need for sentiment analysis of tweets mentioning journal articles. He observed that the "vast majority of tweets [in his study] simply contained variants of the article title or the key conclusion, and rarely contained explicit positive sentiments...or-even less common-negative sentiments" (p. 16). Several years after this statement, researchers conducted sentiment and content analyses on tweets tracked by Plum Analytics, Altmetric, and Twitter queries that mentioned research papers from established databases (Web of Science) and publishers (e.g. JSTOR, Science Direct, Wiley) (Friedrich, Bowman, \& Haustein, 2015; Friedrich, Bowman, Stock, \& Haustein, 2015; Haustein \& Costas, 2015; Liu \& Fang, 2017; Maleki, 2014; Ortega, 2016; Thelwall, Tsou, Weingart, Holmberg, \& Haustein, 2013; Tsou, Bowman, Ghazinejad, \& Sugimoto, 2015; Vainio \& Holmberg, 2017). The following summary of these studies' results do not include tweets mentioning other types of works available in IRs such as grey literature. The current study addresses this gap in the literature by using works from an IR that 
represent both traditional publications (faculty publications and journals collections) as well as grey literature (conferences and student research collections).

Sentiment analyses examine the feelings (attitudes, emotions, opinions, etc.) expressed in tweets towards the works. Researchers used products such as Sentistrength and Sentiment140 and/or manually coded the tweets in their sentiment analyses (Friedrich, Bowman, \& Haustein, 2015; Friedrich, Bowman, Stock et al., 2015; Thelwall et al., 2013). Regardless of the method, the studies supported the initial observations of Eysenbach (2011): high percentages of neutral sentiments (81.7\% or higher), followed by positive (11.0\% or lower) and negative ( $7.3 \%$ or lower) sentiments (Friedrich, Bowman, \& Haustein, 2015; Friedrich, Bowman, Stock, et al., 2015; Thelwall et al., 2013).

Content analyses evaluate tweets through coding in order to produce quantitative data from qualitative data. Liu and Fang (2017) analyzed the content of tweets in order to discover analysis factors beyond count and sentiment. Their sample of tweets contained four types of attitudes: positive, neutral, somewhat supportive, and negative (Liu and Fang, 2017). Their content analysis differed from previous sentiment analyses because they examined tweets that expressed opinions not in relation to the research paper and coded expansion tweets (e.g. conjecture, humorous response, appeals for action, etc.) as positive rather than neutral (Liu and Fang, 2017).

Content analyses also addressed the authors of tweets (Haustein \& Costas 2015; Maleki, 2014; Ortega, 2016; Thelwall et al., 2013; Tsou et al., 2015; Vainio \& Holmberg, 2017). Studies found conflicting results as to whether the tweets' authors were primarily academics or nonacademics (Maleki, 2014; Tsou et al., 2015; Vainio \& Holmberg, 2017). In their studies, 11\% of users were academics versus $41 \%$ non-academics (Maleki, 2014), 34.4\% of the individual users possessed a PhD (Tsou et al., 2015), and users emphasized their occupational expertise (Vainio \& Holmberg, 2017). Although percentages for Twitter users holding PhDs may not be in the majority, Tsou et al. (2015) argued that they are higher than those who hold a Ph.D. in the general public. Regardless of their status in academia, individuals engaged in tweets more than organizations (Haustein \& Costas, 2015; Tsou et al., 2015). Several studies noted individuals tweeting about their own works, which is considered an indicator of promotion rather than impact (Liu \& Fang, 2017; Maleki, 2014; Ortega, 2016; Thelwall et al., 2013).

The results of the content and sentiment analyses informed discussions on how to improve Twitter metrics (Liu \& Fang, 2017; Thelwall et al., 2013). Liu and Fang (2017) favored a weight system in which positive tweets would be weighted more than neutral tweets. They proposed omitting tweets 
featuring an affiliated author, opinions unrelated to the paper, or somewhat supportive and negative attitudes (Liu \& Fang, 2017). In opposition, Thelwall et al. (2013) argued that negative citations do not need to be separated due to their rarity. These suggestions are primarily based on authors' application of Twitter metrics, which does not address the variety of perspectives from altmetrics' stakeholders. The current study addresses this concern by considering the viewpoints of all IR stakeholders (faculty, students, administrators, and academic libraries).

\section{Altmetrics and Institutional Repositories}

Scholars have discussed the capabilities of integrating altmetrics with institutional repositories (Bernal, 2013; Callicott, Scherer, \& Wesolek, 2015; Konkiel \& Scherer, 2013; Madjarevic, 2015; Melero, 2015; Roemer \& Borchardt, 2015a; Roemer \& Borchardt, 2015b; Roemer \& Borchardt, 2015c; Tzoc, 2016; Wesolek, Scherer, Callicott, \& Marsh, 2015). The following outlines the potential benefits and use cases for IR stakeholders when altmetrics are available. Academic libraries can establish the value of works within IRs, encourage others to deposit works in IRs, locate what groups are using their content, and educate institutions on altmetrics (Bernal, 2013; Burns \& Inefuku, 2015; Konkiel \& Scherer, 2013; NISO, 2016; Roemer \& Borchardt, 2015b). Authors (faculty, students) of the IRs' content can showcase the impact of their works in times of evaluation (e.g. grants, promotion and tenure) as well as identify potential collaborators and topics with high public interest (Burns and Inefuku, 2015, Konkiel \& Scherer, 2013; NISO, 2016). The IR platform Digital Commons has the ability to host journals edited and conferences organized by institutions' faculty, students, and/or administrators. These stakeholders can demonstrate the influence of their journals or conferences, focus on popular themes or topics, and encourage authors to contribute their research (NISO, 2016). Lastly, administrators can exhibit the impact of their institutions' scholarly outputs, whether to request budget increases from university trustees or recruit potential faculty and students (Burns \& Inefuku, 2015; Konkiel \& Scherer, 2013; NISO, 2016). They can also utilize altmetrics to evaluate which projects to fund, determine return on investments on that funding, and create benchmarks for groups on campus (Konkiel \& Scherer, 2013). These potential benefits represent the possibilities of altmetrics rather than the reality. The current study showcases a real world example of Twitter metrics that IR stakeholders would receive in order to better understand the practical benefits and uses of altmetrics.

Out of all the stakeholders, academic libraries are becoming the gatekeepers of metrics measuring institutions' scholarly output. Within the scholarly communications field, altmetrics have 
become a core competency for librarians and a popular topic in professional development (Cross, Oleen, \& Perry, 2017; North American Serials Interest Group, 2017). Libraries have published on their experiences of integrating altmetrics with their IRs without delving into the systematic evaluation of altmetrics (Collister \& Taylor, 2017; Wong \& Vital, 2017). Even researchers selected IRs and libraries as the most trusted source of altmetrics (Zhang \& Jackson, 2016). Given the interest among academic libraries and support among researchers, there is a need for more scholarship that explores the relationship between IRs and altmetrics.

\section{Methods}

The author conducted a content analysis of tweets extracted from Georgia Southern University’s PlumX Metrics (https://plu.mx/georgiasouthern/g) mentioning works from four collections in their institutional repository (IR), Digital Commons@Georgia Southern (https://digitalcommons.georgiasouthern.edu/): journals edited by university faculty, conferences organized by university faculty, student research (i.e. undergraduate honors theses, graduate theses and dissertations), and faculty publications. The journals, conferences, and student research collections consisted of works originally published in the IR (or previous IR platform), while the faculty publications collection consisted of works originally published by outside publishers. The author coded information on the tweets' attitudes, authors, audience, hashtags, and URLs. Content analysis was chosen due to its flexibility in coding, specifically the inclusion of tweets with opinions unrelated to the works and expansion tweets as mentioned by Liu \& Fang (2017).

The data in this study includes the tweets in Georgia Southern's PlumX Metrics and the works in Digital Commons@Georgia Southern (within the four collections) that were available on October 26, 2016. This includes any tweets and works published on or prior to this date. The The author collected the tweets' content and publication dates, the tweeted works' titles, associated collections, disciplines, and original publication dates, and the URLs to the PlumX Metrics and Digital Commons records. Three percent (290 of 9671$)$ of the works were mentioned in tweets and eligible for analysis (see Table 1). The works mentioned in tweets were primarily published from 2013 to 2016 within the fields of education, medicine and health sciences, and social and behavioral sciences (see Table 2). Due to individual works having multiple tweets, 605 tweets were available for the analysis. The majority of tweets were posted from 2013 to 2016 and mentioned works within the faculty publications collection followed by journals, conferences, and student research collections (see Table 3). 


\section{Table 1}

Total Works Versus Tweeted Works by Collection

\begin{tabular}{lccc}
\hline Collection & Total works & Tweeted works & $\%$ \\
\hline Journals & 636 & 57 & 9.0 \\
Conferences & 4236 & 46 & 1.1 \\
Student Research & 2751 & 35 & 1.3 \\
Faculty Publications & 2048 & 152 & 7.4 \\
Total & 9671 & 290 & 3.0 \\
& & & \\
\hline
\end{tabular}

The tweets were coded into three primary attitude categories (neutral, positive, negative) with more detailed subcategories. Neutral subcategories reflected information about the work mentioned in the tweets such as title, author, author's affiliation, title of conference or publication, date, reference to Digital Commons, paraphrase of a main idea, and/or quote. Positive subcategories expressed the following within the tweet: excitement for attending a conference, congratulations for publishing, announcement of a new publication, positive opinion about the work, statement of reading/checking out a work, or recommendation to read the work. Negative tweets either expressed a negative opinion about the work's content, price, or the act of reading it. The author categories defined who wrote the tweets based on their relation to the work, including unaffiliated individuals and organizations, affiliated authors and organizations, and colleagues of the works' authors. The audience categories indicated if the tweets were intended for a general audience, specific Twitter user(s), or Twitter user(s) affiliated with the work. Lastly, it was noted whether or not hashtags (keywords following a pound symbol) were included in the tweets. Then, subcategories were created based on the content of the hashtags such as information about the work (author, author's affiliation, conference/publication, date, subject, and title) and other information (365 challenge, Twitter chat, class title, unaffiliated organization and topics, research, Twitter handle, and Twitter handle's affiliation). Consult Appendix A for descriptions and examples of the coding categories for attitude, authors, audience, and hashtags. 


\section{Table $\mathbf{2}^{1}$}

Disciplines and Dates of Tweeted Works

\begin{tabular}{lcc}
\hline Categories & $n$ & $\%$ \\
\hline Disciplines & 10 & 3.4 \\
Arts and Humanities & 5 & 1.7 \\
Business & 115 & 39.7 \\
Education & 4 & 1.4 \\
Engineering & 27 & 9.3 \\
Life Sciences & 61 & 21.0 \\
Medicine and Health Sciences & 14 & 4.8 \\
Physical Sciences and Mathematics & 63 & 21.7 \\
Social and Behavioral Sciences & & \\
Date & 47 & 16.2 \\
2016 & 73 & 25.2 \\
2015 & 75 & 25.9 \\
2014 & 45 & 15.5 \\
2013 & 24 & 8.3 \\
2012 & 9 & 3.1 \\
2011 & 3 & 1.0 \\
2010 & 7 & 2.4 \\
2009 & 3 & 1.0 \\
2008 & 3 & 1.0 \\
2007 & 1 & 0.3 \\
1978 & & \\
\hline
\end{tabular}

${ }^{1} N=290$. Dates do not correspond with the posting date in Digital Commons. For example, the student research collection includes digitized theses and dissertations whose original publication date represented in the table is earlier than the posted date in Digital Commons. 


\section{Table $3^{2}$}

Tweets by Collection and Date

\begin{tabular}{lcc}
\hline Category & $n$ & $\%$ \\
\hline Collection & 123 & 20.3 \\
Journals & 52 & 8.6 \\
Conferences & 42 & 6.9 \\
Student Research & 388 & 64.1 \\
Faculty Publications & & \\
Date & 157 & 26.0 \\
2016 & 174 & 28.8 \\
2015 & 127 & 21.0 \\
2014 & 113 & 18.7 \\
2013 & 31 & 5.1 \\
2012 & 3 & 0.5 \\
2011 & & \\
\hline
\end{tabular}

\section{Results}

In terms of attitude for all tweets, 64.8 percent ( $n=392)$ were neutral, 33.4 percent ( $n=202)$ were positive, and 1.8 percent $(n=11)$ were negative. The most common attitude subcategories were neutral tweets mentioning the works' title (48.4\%), positive tweets expressing opinions about the works (15.5\%), and neutral tweets paraphrasing the works (13.9\%). The other subcategories represented 10.0 percent or less of the tweets. Unaffiliated individuals (51.7\%) or organizations (22.8\%) authored most of the tweets. Affiliated authors (13.7\%), organizations (11.2\%), and colleagues (0.5\%) wrote approximately a quarter of the tweets. 80.3 percent of tweets were meant for a general audience, with 12.5 percent mentioning specific user(s), and 7.8 percent mentioning user(s) affiliated with the work. The majority of the tweets (64.1\%) did not have hashtags. Title (31.8\%), subject (25.8\%), and outside topics (12.0\%) were the most common hashtags with the remainder categories falling below 10 percent. Review Table 4 and Table 5 for comprehensive numbers and percentages of attitude, author, audience, and hashtag categories and subcategories based on all, neutral, positive, and negative tweets.

\footnotetext{
${ }^{2} N=605$
} 


\section{Neutral Tweets}

The neutral tweets represented the majority with 392 tweets out of 605 tweets or 64.8 percent of the tweets. The neutral tweets overwhelmingly included the titles of the works (74.7\%). Approximately one-fifth (21.4\%) paraphrased either the content or title of the works. Lastly, 12.5 percent included the author's name and 10.2 percent provided the conference or publication information. Other neutral attitude subcategories had percentages lower than 10.0 percent each. Individuals (52.8\%) and organizations (29.8\%) unaffiliated with the works wrote the most tweets. The next highest were affiliated organizations (9.2\%) followed by authors (8.2\%). Most tweets (92.3\%) were written for a general audience with no mention of other Twitter accounts. The majority of tweets (69.4\%) did not have hashtags associated with them. Hashtags included keywords from the titles $(37.3 \%)$ or subjects associated with the works (30.0\%). Other categories had 10 percent or less each.

\section{Positive Tweets}

The positive tweets had the second largest size with 202 tweets out of 605 tweets or 33.4 percent of the tweets. This included expressing positive opinions (46.5\%), announcements of new publications (24.8\%), and recommendations (15.8\%). Other subcategories represented 4 to 5 percent each. Unaffiliated individuals (47.5\%) and organizations (9.9\%) wrote the most tweets. Affiliated authors (25.2\%), organizations (15.8\%), and colleagues (1.5\%) wrote a significant portion of the tweets. As for the audiences, 56.9 percent of the positive tweets were intended for a general audience, 31.2 percent were for a specific audience, and 13.9 percent were affiliated communication. Roughly half of the tweets (52.5\%) did not have hashtags. Hashtags subcategories included outside topics (26.4\%), titles $(24.3 \%)$, and subjects (20.1\%). The rest of the hashtags subcategories were less than 10 percent each.

\section{Negative Tweets}

Only 11 negative tweets existed out of 605 tweets, or 1.8 percent of tweets. The negative tweets primarily expressed concerns about the content of the work (81.8\%) with a small percentage commenting on the price of the work (9.1\%) and the act of reading the work (9.1\%). The majority of the tweets were for a general audience $(81.8 \%)$ by individuals with no affiliation to the works $(90.9 \%)$ and had no hashtags (90.9\%). 
Table $4^{3}$

Attitudes, Authors, Audience, and Hashtags of Tweets

\begin{tabular}{|c|c|c|c|c|c|c|c|c|}
\hline \multirow[b]{2}{*}{ Category and subcategory } & \multicolumn{2}{|c|}{$\begin{array}{c}\text { All } \\
\text { Tweets }\end{array}$} & \multicolumn{2}{|c|}{$\begin{array}{l}\text { Neutral } \\
\text { Tweets }\end{array}$} & \multicolumn{2}{|c|}{$\begin{array}{l}\text { Positive } \\
\text { Tweets }\end{array}$} & \multicolumn{2}{|c|}{$\begin{array}{l}\text { Negative } \\
\text { Tweets }\end{array}$} \\
\hline & $n$ & $\%$ & $n$ & $\%$ & $n$ & $\%$ & $n$ & $\%$ \\
\hline \multicolumn{9}{|l|}{ Attitude } \\
\hline Neutral - Author & 49 & 8.1 & 49 & 12.5 & - & - & - & - \\
\hline Neutral - Author's Affiliation & 16 & 2.6 & 16 & 4.1 & - & - & - & - \\
\hline Neutral - Conference/Publication & 40 & 6.6 & 40 & 10.2 & - & - & - & - \\
\hline Neutral - Date & 11 & 1.8 & 11 & 2.8 & - & - & - & - \\
\hline Neutral - Digital Commons & 3 & 0.5 & 3 & 0.8 & - & - & - & - \\
\hline Neutral - N/A & 10 & 1.7 & 10 & 2.6 & - & - & - & - \\
\hline Neutral - Paraphrase & 84 & 13.9 & 84 & 21.4 & - & - & - & - \\
\hline Neutral - Quote & 11 & 1.8 & 11 & 2.8 & - & - & - & - \\
\hline Neutral - Title & 293 & 48.4 & 293 & 74.7 & - & - & - & - \\
\hline Positive - Congratulations & 10 & 1.7 & - & - & 10 & 5.0 & - & - \\
\hline Positive - Excited (Publication) & 50 & 8.3 & - & - & 50 & 24.8 & - & - \\
\hline Positive - Excited (Conference) & 8 & 1.3 & - & - & 8 & 4.0 & - & - \\
\hline Positive - Opinion & 94 & 15.5 & - & - & 94 & 46.5 & - & - \\
\hline Positive - Reading/Checking Out & 8 & 1.3 & - & - & 8 & 4.0 & - & - \\
\hline $\begin{array}{l}\text { Positive - Recommended } \\
\text { Reading }\end{array}$ & 32 & 5.3 & - & - & 32 & 15.8 & - & - \\
\hline Negative-Opinion & 9 & 1.5 & - & - & - & - & 9 & 81.8 \\
\hline Negative - Price & 1 & 0.2 & - & - & - & - & 1 & 9.1 \\
\hline Negative - Reading & 1 & 0.2 & - & - & - & - & 1 & 9.1 \\
\hline \multicolumn{9}{|l|}{ Authors } \\
\hline Individual (Unaffiliated) & 313 & 51.7 & 207 & 52.8 & 96 & 47.5 & 10 & 90.9 \\
\hline Organization (Unaffiliated) & 138 & 22.8 & 117 & 29.8 & 20 & 9.9 & 1 & 9.1 \\
\hline Individual (Affiliated) & 83 & 13.7 & 32 & 8.2 & 51 & 25.2 & - & - \\
\hline Organization (Affiliated) & 68 & 11.2 & 36 & 9.2 & 32 & 15.8 & - & - \\
\hline Individual (Colleague) & 3 & 0.5 & - & - & 3 & 1.5 & - & - \\
\hline \multicolumn{9}{|l|}{ Audience } \\
\hline General & 486 & 80.3 & 362 & 92.3 & 115 & 56.9 & 9 & 81.8 \\
\hline Affiliate & 47 & 7.8 & 19 & 4.8 & 28 & 13.9 & - & - \\
\hline Specific & 76 & 12.5 & 11 & 2.8 & 63 & 31.2 & 2 & 18.2 \\
\hline \multicolumn{9}{|l|}{ Hashtags } \\
\hline Hashtags & 217 & 35.9 & 120 & 30.6 & 96 & 47.5 & 1 & 9.1 \\
\hline No Hashtags & 388 & 64.1 & 272 & 69.4 & 106 & 52.5 & 10 & 90.9 \\
\hline
\end{tabular}

\footnotetext{
${ }^{3}$ Percentages are based on the total number of tweets within the attitude category. $\mathrm{N}$ for all tweets $=605 ; \mathrm{Nfor}$ neutral tweets $=392 ; \mathrm{Nfor}$ positive tweets $=202 ; \mathrm{Nfor}$ negative tweets $=11$. Multiple neutral attitude subcategories and audience categories could be featured in a single tweet resulting in percentages that do not equal 100.
} 


\section{Table $5^{4}$}

Hashtag Subcategories

\begin{tabular}{|c|c|c|c|c|c|c|c|c|}
\hline \multirow[b]{2}{*}{ Subcategory } & \multicolumn{2}{|c|}{$\begin{array}{c}\text { All } \\
\text { Tweets }\end{array}$} & \multicolumn{2}{|c|}{$\begin{array}{l}\text { Neutral } \\
\text { Tweets }\end{array}$} & \multicolumn{2}{|c|}{$\begin{array}{l}\text { Positive } \\
\text { Tweets }\end{array}$} & \multicolumn{2}{|c|}{$\begin{array}{c}\text { Negative } \\
\text { Tweets }\end{array}$} \\
\hline & $n$ & $\%$ & $n$ & $\%$ & $n$ & $\%$ & $n$ & $\%$ \\
\hline 365 Challenge & 3 & 0.9 & - & - & 2 & 1.4 & 1 & 100 \\
\hline Author & 1 & 0.3 & 1 & 0.5 & - & - & - & - \\
\hline Author's Affiliation & 10 & 2.9 & 9 & 4.4 & 1 & 0.7 & - & - \\
\hline Chat & 25 & 7.2 & 19 & 9.3 & 6 & 4.2 & - & - \\
\hline Class Title & 15 & 4.3 & 10 & 4.9 & 5 & 3.5 & - & - \\
\hline Conference/Publication & 17 & 4.9 & 11 & 5.4 & 6 & 4.2 & - & - \\
\hline Date & 1 & 0.3 & - & - & 1 & 0.7 & - & - \\
\hline Research & 5 & 1.4 & 4 & 2.0 & 1 & 0.7 & - & - \\
\hline Outside Organization & 18 & 5.2 & 4 & 2.0 & 14 & 9.7 & - & - \\
\hline Outside Topics & 42 & 12.0 & 4 & 2.0 & 38 & 26.4 & - & - \\
\hline Subject & 90 & 25.8 & 61 & 30.0 & 29 & 20.1 & - & - \\
\hline Title & 111 & 31.8 & 76 & 37.3 & 35 & 24.3 & - & - \\
\hline Twitter Handle & 4 & 1.1 & 2 & 1.0 & 2 & 1.4 & - & - \\
\hline Twitter Handle’s Affiliation & 7 & 2.0 & 3 & 1.5 & 4 & 2.8 & - & - \\
\hline
\end{tabular}

\section{URLS}

The tweets from the journals, conferences, student research collections included links to the institutional repository (IR). The tweets from the faculty publications collection included links to other websites where the works were published such as publisher websites, preprint databases, etc. The exception was one URL to a faculty member's profile within the IR.

\section{Discussion}

Despite the limited sample size, the results parallel other studies' findings including low percentage of tweeted works, high percentage of neutral attitudes in tweets, and evidence of selfmentions. The discussion expands on the meaning of these trends and other results specific to this study including the high percentage of tweets for a general audience, evidence of networking hashtags, and URLs leading to the institutional repository (IR) and original publishers' websites. The

\footnotetext{
${ }^{4}$ Percentages are based on the total number of hashtags within the attitude category. $N$ for all tweets $=349 ; N$ for neutral tweets $=204 ; N$ for positive tweets $=144 ; N$ for negative tweets $=1$.
} 
discussion considers the unique perspectives of different IR stakeholders (faculty, students, administrators, and academic libraries). This differs from previous research that primarily considered the authors of journal articles when discussing improvements for Twitter metrics (Friedrich, Bowman, \& Haustein, 2015; Friedrich, Bowman, Stock, et al., 2015; Haustein \& Costas, 2015; Liu \& Fang, 2017; Maleki, 2014; Ortega, 2016; Thelwall et al., 2013; Tsou et al., 2015, Vanio \& Holmberg, 2017). Libraries managing IRs have an important point-of-view given their centrality to metrics on campus. Faculty who are editors and organizers of the journals and conferences collections may also share a similar perspective with academic libraries in addition to their perspective as authors.

\section{Low Numbers}

Only three percent of the works had affiliated tweets, which is slightly less than the percentages in studies by Ortega (2016) (9.2\%) and Maleki (2014) (5\%). ${ }^{5}$ Grey literature may be the cause as the conferences and student research collections had less tweets than the traditional publications (journals and faculty publications collections). Schöpfel \& Prost (2016) argued that this may due to less stable identifiers. Since a small portion of the grey literature migrated from a previous repository platform, tweets that mentioned their previous URLs may not have been tracked. This reiterates the importance of assigning DOIs to records in student research, journals, and conferences collections featured in IRs. Low percentages of tweeted works means limited chances for IR stakeholders to take advantage of Twitter metrics. If quantitative Twitter data is limited, IR stakeholders may exclude the number of tweets when reporting impact (e.g. tenure/promotion reviews, institutional research outputs, annual IR reports) to avoid inconsistency or the appearance of inadequacy. Specifically, comparing individual works, academic units, or IR collections becomes unreliable.

\section{Neutral Attitude}

The results of the content analysis are comparable to the previous sentiment analyses with a high percentage of neutral tweets $(64.8 \%)$ followed by positive $(33.4 \%)$ and negative tweets (1.8\%) (Friedrich, Bowman, \& Haustein, 2015; Friedrich, Bowman, Stock et al., 2015; Thelwall et al., 2013). This study had higher rates of positive tweets in comparison to the findings of sentiment analyses. This

\footnotetext{
${ }^{5}$ Ortega (2016) shared a small portion of his dataset with this study. 
could be attributed to content analyses having broader coding categories for positive tweets. Approximately half of the positive tweets from this study did not express opinions about the works and were comparable to neutral tweets' implicit messages of agreement or relevancy to their followers (Thelwall et al., 2013).

Since neutral tweets have demonstrated to be the most common attitude or sentiment, Twitter metrics would benefit from borrowing the trends of citation metrics that ignore sentiment or attitude (Thelwall et al., 2013). Liu and Fang (2017) suggested excluding negative tweets and weighting certain positive tweets. However, these actions would not drastically change the metrics due to the low numbers of non-neutral tweets found in previous studies. Although this study had more positive tweets, distinguishing between different types of positive attitudes or sentiments would be difficult, especially with those that are similar to the implicit meaning of neutral tweets.

Based on the high probability of neutral tweets, Twitter metrics indicate attention or visibility rather than high-levels of impact. Twitter metrics may be used to determine what subjects are receiving the most buzz in order to inform decisions on what to pursue for research projects (faculty and student authors), funding (administrators), or IR collections (academic libraries). In terms of qualitative data, positive and negative tweets have potential benefits for faculty and student authors, because they can pinpoint which part of the works garnered the most interest or criticism. Unfortunately, discovering a tweet that expresses that information may be scarce due to the low numbers of tweets and high chances of neutral tweets.

\section{Self-Mentions}

In this study, roughly a quarter of the tweets were authored by individuals or organizations affiliated with the cited works. Self-mentions were more common in positive tweets than neutral and negative tweets. Other studies have noted their observation of self-mentions (Liu \& Fang, 2017; Maleki, 2014; Ortega, 2016; Thelwall et al., 2013). Based on the commonality of self-mentions, separating tweets by affiliated individuals and organizations would be beneficial. For authors (faculty and students) and administrators, self-mentions could change the meaning of their metrics by indicating promotional effort rather than attention or visibility (Ortega, 2016). Authors and administrators may choose to extract self-mentions from their reports because of this representation of promotion. In contrast, academic libraries may use self-mentions as evidence that internal stakeholders are utilizing and interacting with their IRs. Given the different meanings for stakeholders, separating the self- 
mentions would be more preferential than completely excluding them as suggested by Liu and Fang (2017). Altmetric (2018) addresses promotional intent in their 'Attention Score' by considering whether the tweets' authors have previously tweeted multiple times about the same journal. However, the list of tweets are not separated by affiliated authored tweets and unaffiliated authored tweets. Altmetric (2017a) also provides the demographics of the tweets' authors (member of public, researcher, practitioner, science communicator). While this study focused on unaffiliated versus affiliated authors, demographics of Twitter users shed light on whether the attention is from those within or outside academia.

\section{General Audience}

In the current study, the majority of tweets (80.4\%) were intended for a general audience rather than specific follower(s). Tweeting to a general audience indicates that the tweets were intended for the users' followers and potentially the Twittersphere. Presumably, tweets from Twitter users with many followers would have a higher chance for retweets, replies, likes, and consequently, more views of the scholarly works mentioned in the tweets. Ortega (2016) studied Twitter users who authored research papers and discovered that "the total number of tweets posted by the authors and the number of followers they have, positively influence the times that papers are tweeted" (p. 1358). However, Cha, Haddadi, Benevenuto, and Gummadi (2011) found that followers indicated popularity, not influence in terms of engaging the audience (retweets and mentions). In order to have a comprehensive overview of the tweets' reach and influence, metrics aggregators should provide the number of followers, retweets, replies, and likes in addition to the content of the individual tweets. Since Twitter metrics is a representation of social media, all stakeholders would benefit from knowing the full extent of the tweets' reach in order to grasp their influence. Altmetric has incorporated these elements into their 'Attention Score.' It is a weighted count that considers a tweet's retweets, reposts, and followers, as well as how often the Twitter user tweets about research output and if they tweet multiple times about the same journal (Altmetric, 2018).

\section{Networking Hashtags}

The majority of tweets (64.1\%) in the current study did not have hashtags. The most common hashtags were created from keywords in the title and subjects related to the works. Three types of hashtags from the tweets could have value for networking purposes: chat, class title, and outside 
conference. These hashtags represented discussions on a specific subject (chat), between a higher education course (class title), and during events unaffiliated with the work (outside conference). Faculty and student authors who use Twitter for its networking capabilities would benefit the most from these hashtags (Veletsianos, 2011; Veletsianos \& Kimmons, 2016). Unfortunately, this potential benefit would be unlikely as these categories represented only five percent of all hashtags.

Administrators and IR managers do not obtain as much value from hashtags, unless they have Twitter accounts to promote the institutions' or IRs' scholarly works. In these cases, institutional Twitter accounts could use the hashtags to communicate and promote the scholarship of the institution and IR to focused groups of Twitter users.

\section{Repository vs. Publisher URLs}

The tweets mentioning works originally published in the IR (journals, conferences, student research collections) linked to the IR. The tweets mentioning works originally published outside the IR (faculty publications collection) primarily linked to outside websites. It should be noted that metrics aggregators must have an identifier to track scholarly works. For example, presentations at conferences will not be tracked unless the tweets include certain identifier(s) (URLs, DOIs, etc.). If an attendee tweets about a presentation with the hashtag for the conference, but without the correct identifier, then it will not be captured. IR stakeholders need to consider the need for an identifier in order to accurately capture tweets about works in the IR.

The URLs' destinations may affect the stakeholders' perceived value of the tweets. Authors (faculty and students) and administrators would benefit from collecting tweets from every possible source, because they are all relevant in measuring attention on their affiliated works. In contrast, academic libraries may want to separate the tweets that link to IRs from those linking to other sources. The former demonstrates the attention IRs receive as a publishing platform in contrast to demonstrating the impact of the institutions' scholarly works. Since altmetrics accumulate immediately after publication, IR managers will want to continue to request that authors include their works (preprints, postprints, presentations) in their IRs before the works are published on another website to increase the chances that the tweets will refer to the IRs' URLs (Holmberg et al., 2015). 


\section{Limitations}

The results represent a single institution's data and cannot be applied broadly. Participation within the institutional is voluntary with the exception of the student research collection. The subject areas of the tweeted works were concentrated in education, medicine and health sciences, and social and behavioral sciences, which could have affected the types of tweets the study collected (Friedrich, Bowman, \& Haustein, 2015; Vainio \& Holmberg, 2017).

\section{Conclusion}

Institutional repositories (IRs) are the central hub for the scholarly output of higher education institutions, which means the entire campus has stakes in the success of the IR. IR stakeholders (faculty, students, administrators, and academic libraries) have varying motivations and purposes for

using IRs. The integration of altmetrics with IRs can enhance the IRs' value to stakeholders by offering the ability to demonstrate impact. As managers of IRs, academic libraries can become responsible for the accuracy, promotion, and reporting of altmetrics across campus. This may entail changing metadata standards to ensure optimal integration with the altmetrics product, promoting the value of altmetrics on campus, instructing administrators and faculty how to report altmetrics, and creating reports for them. Therefore, altmetrics research with a focus on scholarly outputs in IRs are important to explore.

This study was successful in providing a snapshot of the tweets tracked by a metrics aggregator in connection to an IR. It helps inform how beneficial tweets may be for different stakeholders and ways to improve Twitter metrics. However, this study represents a miniscule portion of the major potential for altmetrics studies revolving around academic libraries and IRs. Further research needs to investigate the broad range of altmetrics (Mendeley, Facebook, Reddit, etc.) as well as produce a larger sample size by examining multiple IRs. Qualitative studies need to focus on the motivations of IR stakeholders. For example, interviewing or surveying stakeholders on their perception of altmetrics in IRs can further determine if the potential use cases have real world value. The more altmetrics research focus on IRs, the more informed academic libraries, and consequently others on campus, will become on interpreting and utilizing altmetrics. 


\section{References}

Altmetric. (2017a). How are Twitter demographics determined? Retrieved from https://help.altmetric.com/support/solutions/articles/6000060978-how-are-twitter demographics-determined-

Altmetric. (2017b). How does Altmetric track Twitter?Retrieved from https://help.altmetric.com/support/solutions/articles/6000157183-how-does-altmetric track-

twitter-

Altmetric. (2018). How is the Altmetric Attention Score calculated? Retrieved from https://help.altmetric.com/support/solutions/articles/6000060969-how-is-the-altmetric attention-score-calculated-

Barnes, C. (2015). The use of altmetrics as a tool for measuring research impact. Australian Academic \& Research Librarian, 46(2), 121-134. doi:10.1080/00048623.2014.1003174

Bernal, I. (2013). Open access and the changing landscape of research impact indictors: new roles for repositories. Publications, 1(2), 56-77. doi:10.3390/publications1020056

Burns, T., \& Inefuku, H.W. (2015a). Purposeful metrics: matching institutional repositorymetrics to purpose and audience. In B. B. Callicott, D. Scherer, \& A. Wesolek (Eds.), Making institutional repositories work(pp. 213-234). West Lafayette, IN: Purdue University Press.

Callicott, B.B., Scherer, D., \& Wesolek, A. (Eds.). (2015). Making institutional repositories work. West Lafayette, IN: Purdue University Press.

Cha, M., Haddadi, H., Benevenuto, F., \& Gummadi, K.P. (2010). Measuring User Influence in Twitter: The Million Follower Fallacy. Proceedings of the Fourth International AAA/ Conference on Weblogs and Social Media (pp. 20-17). Retrieved from https://www.aaai.org/ocs/index.php/ICWSM/ICWSM10/paper/download/1538/1826 
Collister, L. \& Taylor, A. (2017). Altmetrics, legacy scholarship, and scholarly legacy. Pennsylvania Libraries: Research \& Practice, 1(2), 127-137. Retrieved from http://palrap.pitt.edu/ojs/index.php/palrap/article/view/154

Cross, W., Oleen, J., and Perry, A. (2017). Jump start your scholarly communication initiatives: Lessons learned from redesigning the scholarly communications roadshow for a new generation of librarians. At the Helm: Leading Transformation, the Proceedings of the ACRL 2017 Conference (pp. 361-371). Retrieved from http://www.ala.org/acrl/sites/ala.org.acrl/files/content/conferences/confsandpreconfs/2017/J umpStartYourScholarlyCommunicationInitiatives.pdf

Erdt, M., Nagarajan, A., Joanna, S-C.S., \& Theng, Y-L. (2016). Altmetrics: an analysis of the state-of-theart in measuring research impact on social media. Scientometrics, 109(2), 1117-1166, doi:10.1007/s11192-016-2077-0

Eysenbach, G. (2011). Can tweets predict citations? Metrics of social impact based on twitter and correlation with traditional metrics of scientific impact. Journal of Medical Internet Research, 13(4), 1-20. doi:10.2196/jmir.2012

Friedrich, N., Bowman, T.D., \& Haustein, S. (2015). Do tweets to scientific articles contain positive or negative sentiments. Paper presented at the 2015 Altmetrics Workshop, Amsterdam. Retrieved from http://altmetrics.org/altmetrics15/friedrich/

Friedrich, N., Bowman, T.D., Stock, W.G., \& Haustein, S. (2015). Adapting sentiment analysis for tweets linking to scientific papers. In Proceedings of the 15th International Society of Scientometrics and Informetrics Conference (pp. 107-108). Istanbul, Turkey. 
Haustein, S., \& Costas, R. (2015). Identifying Twitter audiences: who is tweeting about scientific papers. Paper presented at the ASIS\&T SIG/MET Metrics 2015 workshop. Retrieved from https://www.asist.org/SIG/SIGMET/wp-content/uploads/2015/10/sigmet2015 paper 11.pdf

Holmberg, K., Haustein, S., \& Beucke, D. (2015). Social media metrics as indicators of repository. In B. B. Callicott, D. Scherer, \& A. Wesolek (Eds.), Making institutional repositories work (pp. 235-248). West Lafayette, IN: Purdue University Press.

Konkiel, S., \& Scherer, D. (2013). New opportunities for repositories in the age of altmetrics. Bulletin of the Association for the Information Science and Technology, 39(4), 22-26. doi:10.1002/bult.2013.1720390408

Liu, X.Z., \& Fang, H. (2017). What we can learn from tweets linking to research papers. Scientometrics, 111, 349-369, doi:10.1007/s11192-017-2279-0

Madjarevic, N. (2015). Connecting Altmetric: integrating with institutional publication system. F1000Research, 4, 192. doi:10.12688/f1000research.6517.1

Maleki, A. (2014). Twitter users in science tweets linking to articles: The case of web of science articles with Iranian authors. In SIGMET Workshop METRICS 2014. Seattle, WA: American Society for Information Science and Technology. Retrieved from http://www.asis.org/SIG/SIGMET/data/uploads/sigmet2014/maleki.pdf Melero, R. (2015). Altmetrics - a complement to conventional metrics. Biochemia Medica, 25(2), 152160. doi:10.11613/BM.2015.016

National Information Standards Organization (NISO). (2016). Outputs of the NISO Alternative Assessment Metrics Project. Baltimore: National Information Standards Organization. Retrieved from http://www.niso.org/topics/tl/altmetrics initiative/ 
North American Serials Interest Group, Inc., NASIG Core Competencies for Scholarly Communication Librarians. Retrieved from http://www.nasig.org/site_page.cfm?pk_association_webpage_menu=310\&pk_association_w ebpage $=9435$

Ortega, J.L. (2016). To be or not to be on twitter, and its relationship with tweeting and citation of research papers, Scientometrics, 109(2), 1353-1364. doi:10.1007/s11192-016-2113-0

Plum Analytics. (2018). Social Media Metrics. Retrieved from https://plumanalytics.com/learn/aboutmetrics/social-media-metrics/

Roemer, R.C., \& Borchardt, R. (2015a). Chapter 2. Major Altmetrics Tools. Library Technology Reports, 51(5), 11-19. Retrieved from https://journals.ala.org/index.php//tr/article/view/5746

Roemer, R.C., \& Borchardt, R. (2015b). Chapter 4. Altmetrics and the Role of Librarians. Library Technology Reports, 51(5), 31-37. Retrieved from https://journals.ala.org/index.php/ltr/article/view/5748

Roemer, R.C., \& Borchardt, R. (Eds.). (2015c). Meaningful metrics: A 21st-century librarian's guide to bibliometrics, altmetrics, and research impact. Chicago, IL: Association of College and Research Libraries.

Schöpfel, J. \& Prost, H. (2016). Altmetrics and grey literature: perspectives and challenges. Paper presented at the GL18 International Conference on Grey Literature. Retrieved from http://hal.univ-lille3.fr/hal-01405443

Thelwall, M., Tsou, A., Weingart, S., Holmberg, K., \& Haustein, S. (2013). Tweeting links to academic articles. Cybermetrics: International Journal of Scientometrics, Infometrics and Bibliometrics, $17,1-8$ 
Tsou, A. Bowman, T., Ghazinejad, A., \& Sugimoto, C. (2015). Who tweets about science? In Proceedings of the 15th International Society of Scientometrics and Informetrics Conference. (pp. 95-100). Instanbul, Turkey.

Tzoc, E. (2016). Institutional repository software platforms at undergraduate libraries in the United States. College \& Undergraduate Libraries, 23(2), 184-192, doi:10.1080/10691316.2014.959230

Vainio, J. \& Holmberg, K. (2017). Highly tweeted science articles: who tweets them? An analysis of twitter user profile descriptions. Scientometrics, 112(1), 345-366, doi:10.1007/s11192-017-2368$\underline{0}$

Veletsianos, G. (2011). Higher education scholars' participation and practices on twitter. Journal of Computer Assisted Learning, 28(4), 336-349. doi:10.1111/j.1365-2729.2011.00449.x

Veletsianos, G., \& Kimmons, R. (2016). Scholars in an increasingly open and digital world: how do education professors and students use Twitter? The Internet and Higher Education, 30, 1-10, doi:10.1016/j.iheduc.2016.02.002

Wesolek, A., Scherer, D., Callicott, B.B., \& Marsh, R.M. (2015). The role of institutional repositories in developing the communication of scholarly research. International Digital Library Perspective, 31(4), 163-195, doi:10.1108/OCLC-04-2014-0022

Wong, E. \& Vital, S. (2017). PlumX: A tool to showcase academic profile and distinction. Digital Library Perspectives 33(4), 305-313. doi:10.1108/DLP-12-2016-0047

Zhang, H., \& Jackson, K. (2016). A measured approach: evaluating altmetrics as a library service. In K. Smith \& K. Dickson (Eds.), Open access and the future of scholarly communication: implementation (pp. 97-128). Lanham, MD: Rowman and Littlefield. 